\title{
Association of Serum Uric Acid and ADA Levels in an Obese With or Without Metabolic Syndrome
}

\author{
V. Durga Prasad ${ }^{1}$, G. Venkataramana ${ }^{2}$ \\ ${ }^{1 .}$ Assistant Professor, Biochemistry, Dr. PSIMS \&RF, Chinavutapalli \\ 2. Professor \& HOD, Biochemistry, Dr. PSIMS \& RF, Chinavutapalli.
}

\begin{abstract}
:
Background: Obesity is a leading cause of mortality and morbidity in world wide. Previous literature demonstrated high ADA activity and uric acid levels in obese than in non obese.

Aim and Objectives: To estimate ADA levels, Lipid profile and serum uric acid levels in an obese and healthy subjects and its clinical significance in predicting the pathogenesis of obesity and MS.

Materials and methods: A group of sixty subjects in which thirty were obese and thirty age sex matched healthy subjects were recruited in this study. We have estimated serum uric acid, ADA levels and lipid profile in both healthy and obese subjects. Waist circumference and BMI is also taken as common metabolic risk factors in both the groups. We have seen these parameters in both obese and healthy subjects.

Results: The metabolic risk parameters shown are statistifically significantly elevated in obese individuals. Elevation of serum uric acid and ADA levels may lead to MS
\end{abstract}

Conclusion: Serum uric acid, ADA is one of the causing factors for obesity pathogenecity.

Keywords: ADA: adenosine deaminase, BMI: body mass index, COPD: chronic obstructive pulmonary disease,MS: metabolic syndrome, $T_{2} D M$ : type 2 Diabetes Mellitus

\section{Introduction}

The Public around the world paying attention to the prevalence of Obesity ${ }^{1}$ due to its association with chronic diseases like breast cancer ${ }^{2}, \mathrm{COPD}^{3}$ and soon. In human beings serum Uric acid is end product of purine metabolism ${ }^{4}$. An elevated level of serum uric acid is an independent risk factor for female abdominal obesity and $\mathrm{MS}^{5}$.

Adenosine is converted to inosine by $\mathrm{ADA}^{6}$. Highest adenosine deaminase(ADA) activity is in lymphoid and fatty tissues, liver, skeletal muscle and heart ${ }^{7}$. ADA activity is increased in obese, $\mathrm{T}_{2} \mathrm{DM}$ patients. So adenosine is responsible for increase of glucose uptake into cells ${ }^{8}$. Thus increasing ADA activity in insulin sensitive tissue will decrease adenosine levels which lead to decrease glucose uptake into cells. However there is still lack of study on association between obesity and serum ADA and Uric acid among adults. The aim of this study is to evaluate the association between obesity and uric acid, ADA, lipid profile, BMI and waist circumference.

\section{Subjects and Methods:}

The definition of obesity cannot be simply made in terms of body weight because we should expect short people to be lighter than tall people. Therefore we need to standardised body weight against body height. The simplest expression for this is the body mass index (BMI) calculated as weight (kg) divided by height squared $\left(\mathrm{m}^{2}\right)$. The World Health Organisation (WHO) guidelines of 1985 defined obesity as a BMI $>30.0$ for men and $>28.6$ for women' the WHO with a BMI over 25 being defined as 'overweight' and over 30 as being 'obese $\mathrm{e}^{10}$.

Total of Sixty subjects were recruited in this study between the ages of 25-45 years. Out of sixty subjects thirty were controls and thirty were age and sex matched Obese subjects. All subjects agreed to provide their personal information regarding the purpose and the procedures of our study and written informed consent. This study was approved by local ethics committee. This study was conducted in department of biochemistry, KIMS Amalapuram. The study was approved by Institutional Ethical Committee (IEC). Written Informed consent of participants was taken prior to study. None of them are smokers, alcoholics, diabetics, hypertensives or suffering from any other illness. In our study Height and weight was measured in light clothing on an electronic scales. And body mass index (BMI) was calculated by dividing the weight $(\mathrm{kg})$ by the height $(\mathrm{m})$ squared. Fasting samples were collected from all the sixty subjects. Serum uric acid was estimated by the uricase method , Total cholesterol by CHOD-PAP, Triglycerides by glycerol phosphate oxidase, HDL by direct method, by using standard enzymatic methods by Randox Daytona autoanalyser. Serum adenosine deaminase measured by ADA-MTB method using semi auto analyzer. 
The results were tabulated in Table 1 and 2.The statistical analysis was done by student " $\mathrm{t}$ " test using graph pad prism version 6.0 software and results were expressed as mean \pm SD. p value $<0.05$ was considered as statistically significant.

\section{Results and Discussion}

Table: 1 showing the comparison of Mean $( \pm S D)$ values of studied parameters among Controls and obese subjects

\begin{tabular}{|c|c|c|c|c|c|}
\hline & PARAMETERS & $\begin{array}{l}\text { Mean } \pm \text { SD } \\
\text { CONTROLS } \\
(n=30)\end{array}$ & $\begin{array}{l}\text { Mean } \pm \text { SD } \\
\text { CASES } \\
(n=30)\end{array}$ & $\mathrm{T}$ & p VALUE \\
\hline 1 & $\begin{array}{lll}\begin{array}{l}\text { Serum } \\
(\mathrm{mg} / \mathrm{dl})\end{array} & \text { Total } & \text { cholesterol } \\
\end{array}$ & $155.37 \pm 2.366$ & $205.40 \pm 28.004$ & 8.952 & $<0.0001$ \\
\hline 2 & $\begin{array}{l}\text { Serum Triglycerides } \\
(\mathrm{mg} / \mathrm{dl})\end{array}$ & $90.133 \pm 17.834$ & $179.70 \pm 67.496$ & 7.027 & $<0.0001$ \\
\hline 3 & Serum HDL(mg/dl) & $46.900 \pm 5.604$ & $38.167 \pm 3.384$ & 7.307 & $<0.0001$ \\
\hline 4 & $\begin{array}{l}\begin{array}{l}\text { SERUM uric acid (SUA) } \\
(\mathrm{mg} / \mathrm{dl})\end{array} \\
\end{array}$ & $3.757 \pm 0.4659$ & $6.160 \pm 0.8775$ & 13.249 & $<0.0001$ \\
\hline 5 & SERUM ADA U/L & $22.533 \pm 3.683$ & $32.067 \pm 5.439$ & 7.949 & $<0.0001$ \\
\hline
\end{tabular}

Table:2 showing Mean ( $\pm S D)$ of age, height, weight and BMI, waist circumference by gender in controls and obese subjects

\begin{tabular}{|c|l|l|l|}
\hline & PARAMETERS & $\begin{array}{l}\text { Mean } \pm \text { SD } \\
\text { CONTROLS }\end{array}$ & $\begin{array}{l}\text { Mean } \pm \text { SD } \\
\text { obese }\end{array}$ \\
\hline 1 & Men( N=10) & $35.1 \pm 6.662$ & $34.4 \pm 6.168$ \\
\hline 2 & Women $(\mathrm{N}=20)$ & $33.15 \pm 5.842$ & $33.85 \pm 5.985$ \\
\hline 3 & HEIGHT in Cms $(\mathrm{n}=30)$ & $160.72 \pm 10.553$ & $163.80 \pm 9.486$ \\
\hline 4 & Weight in Kgs $(\mathrm{n}=30)$ & $53.133 \pm 10.244$ & $80.197 \pm 10.079$ \\
\hline 5 & BMI( $\mathbf{n}=\mathbf{3 0})$ & $20.362 \pm 1.816$ & $31.840 \pm 2.178$ \\
\hline 6 & Waist circumference in Cms $(\mathbf{n}=\mathbf{3 0})$ & $88.567 \pm 4.546$ & $107.20 \pm 7.044$ \\
\hline
\end{tabular}

In our study Total cholesterol levels were statistically significantly increased $(\mathrm{p}<0.0001)$ in obese compared to controls. In our study Triglycerides levels were statistically significantly increased $(p<0.0001)$ in obese compared to controls. In our study HDL cholesterol levels were statistically significantly decreased $(\mathrm{p}<0.0001)$ in obese compared to controls. In the present study cardiometabolic syndrome risk factors of modified NECP ATP III criteria were significantly elevated in obese individuals when compared to controls.

In our study Uric acid levels were statistically significantly increased $(p<0.0001)$ in who had obesity compared to controls. Our study is in accordance with ${ }^{11,12,13}$, .In this study, a positive significant association between serum uric acid and obesity has been found. And the association was stronger in females than males in obesity group, which was consistent with findings in different populations such as people from Bangkok Thailand ${ }^{14}$, middle age Chinese ${ }^{5}$ etc. In obesity population from America demonstrated that serum uric acid influenced obesity but not independently impacted obesity ${ }^{15}$. Thus it is still uncertain whether serum uric acid can be an indicator of obesity. Uric acid is having antioxidant activity in the extracellular environment, once it enters cells including vascular smooth muscle cells (VSMC) and adipocytes, it has detrimental effects ${ }^{16,17}$. Hyperuricemia may predict the development of metabolic syndrome ${ }^{18}$, diabetes mellitus ${ }^{19}$, hypertension ${ }^{20}$, and cardiovascular disorders ${ }^{21}$. These findings support the notion that elevated serum uric acid levels cannot just be viewed as a secondary phenomenon in these pathologies. A recent study supports that insulin resistance has an important role in the causal relationship between metabolic syndrome, and hyperuricemia. ${ }^{22}$. Osgood and colleagues proposed that the serum uric acid not only correlates with concomitant insulin action, blood pressure, and lipid profile; it also predicts future insulin resistance and type 2 diabetes. ${ }^{23}$ •

In our study ADA levels were statistically significantly increased $(\mathrm{p}<0.0001)$ in Obese compared to controls. ADA regulates intracellular and extra cellular concentrations of adenosine ${ }^{24}$. Adenosine increases glucose uptake in the tissues and also inhibits proliferation of T-cells and cytokine synthesis. Thus, ADA 
activity is increased, insulin insensitivity/resistance, cellular proliferation, inflammation, T-cells etc which are associated with the metabolic syndrome also increases ${ }^{25}$.

ADA activities might be a predicting factor in the dyslipidaemias in particular and metabolic diseases in general, and may be used as a diagnostic kit in the daily assessment of the metabolic syndrome. In conclusion, ADA can be used in daily routine laboratory assessment of most metabolic diseases especially in obese and diabetic patients. Thus, targeting ADA in the treatment of metabolic diseases would be very appropriate. Folli et $\mathrm{al}^{26}$ showed that defective signalling from the insulin receptors is an important component of the insulin resistance associated with obesity in both animal models and humans

\section{Conclusions}

In conclusion, serum uric acid was strongly associated with obesity .Further study should be established to explore deep relationship between serum uric acid and Obesity by adding in more obesity related factors. To prevent obesity promoting healthy eating and physical activity is very important.ADA is a non specific diagnostic marker in tuberculosis and it should be further evaluated involving more subjects with different age groups of population.

\section{References}

[1]. Wang, Y. and T. Lobstein, Worldwide trends in childhood overweight and obesity. Int J Pediatr Obes, 2006. 1(1): 11-25.

[2]. Petekkaya, I., U. Sahin, G. Gezgen, M. Solak, D. Yuce, O. Dizdar, et al., Association of breast cancer subtypes and body mass index. Tumori, 2013. 99(2): 129-33.

[3]. Zhou, Y., D. Wang, S. Liu, J. Lu, J. Zheng, N. Zhong, et al., The association between BMI and COPD:the results of two populationbased studies in Guangzhou,China.COPD, 2013.10(5): 567- 72.

[4]. Choi, H.K., D.B. Mount, A.M. Reginato, P. American College of and S. American Physiological, Pathogenesis of gout. Ann Intern Med, 2005. 143(7): 499-516.

[5]. Yin, X., J. Zhou, D. Yu, Q. Pan, X. Dong, F. Zheng, et al., [The correlation between serum uric Acid level and abdominal obesity or metabolic syndrome]. Zhonghua Nei Ke Za Zhi, 2014. 53(1): 13-8.

[6]. N. Spencer, D. A. Hopkinson, and H. Harris, "Adenosine deaminase polymorphism in man," Annals of Human Genetics, 1968 vol. 32, no. 1, pp. 9-14,.

[7]. M. B. van der Weyden and W. N. Kelley, "Human adenosine deaminase. Distribution and properties," The Journal of Biological Chemistry, 1976 vol. 251, no. 18 , pp. 5448-5456,

[8]. L.Vergauwen, P.Hespel, and E.A. Richter, "Adenosine receptors mediate synergistic stimulation of glucose uptake and transport by insulin and by contractions in rat skeletal muscle," The Journal of Clinical Investigation, 1994 vol. 93, no. 3, pp. 974-981,.

[9]. World Health Organisation. Energy and protein requirements. Report of a joint FAO/ WHO/ UNU expert consultation. Geneva, Switzerland: World Health Organisation; 1985. WHO Technical Report Series 724.

[10]. World Health Organisation. The global epidemic of obesity. Geneva, Switzerland: World Health Organisation 1997.

[11]. Chiou, W.K., D.H. Huang, M.H. Wang, Y.J. Lee and J.D. Lin, Significance and association of serum uric acid (UA) levels with components of metabolic syndrome (MS) in the elderly.Arch Gerontol Geriatr, 2012. 55(3): 724-8.

[12]. Liu, M., Y. He, B. Jiang, L. Wu, S. Yang, Y. Wang, et al., Association between Serum Uric Acid Level and Metabolic Syndrome and Its Sex Difference in a Chinese Community Elderly Population. Int J Endocrinol, 2014. 2014: 754678.

[13]. Palmer, T.M., B.G. Nordestgaard, M. Benn, A. Tybjaerg-Hansen, G. Davey Smith, D.A. Lawlor, et al., Association of plasma uric acid with ischaemic heart disease and blood pressure: mendelian randomisation analysis of two large cohorts. BMJ, 2013. 347: f4262.

[14]. Jaipakdee, J., W. Jiamjarasrangsri, V. Lohsoonthorn and S. Lertmaharit, Prevalence of metabolic syndrome and its association with serum uric acid levels in Bangkok Thailand. Southeast Asian J Trop Med Public Health, 2013. 44(3): 512-22.

[15]. Ferrara, L.A., H. Wang, J.G. Umans, N. Franceschini, S. Jolly, E.T. Lee, et al., Serum uric acid does not predict incident metabolic syndrome in a population with high prevalence of obesity. Nutr Metab Cardiovasc Dis, 2014. 24(12): 1360-4

[16]. Sautin YY, Nakagawa T, Zharikov S, Johnson RJ. Adverse effects of the classic antioxidant uric acid in adipocytes: NADPH oxidase-mediated oxidative/nitrosative stress. Am J Physiol-Cell Ph. 2007; 293:C584-C596.

[17]. Corry DB, et al. Uric acid stimulates vascular smooth muscle cell proliferation and oxidative stress via the vascular reninangiotensin system. Journal of hypertension. 2008; 26:269-275.

[18]. Masuo K, Kawaguchi H, Mikami H, Ogihara T, Tuck ML. Serum uric acid and plasma norepinephrine concentrations predict subsequent weight gain and blood pressure elevation. Hypertension. 2003; 42:474-480. [PubMed: 12953019]

[19]. Nakanishi N, et al. Serum uric acid and risk for development of hypertension and impaired fasting glucose or Type II diabetes in Japanese male office workers. Eur J Epidemiol. 2003; 18:523-530. [PubMed: 12908717]

[20]. Sundstrom J, et al. Relations of serum uric acid to longitudinal blood pressure tracking and hypertension incidence. Hypertension. $2005 ; 45: 28-33$.

[21]. Bickel C, et al. Serum uric acid as an independent predictor of mortality in patients with angiographically proven coronary artery disease. Am J Cardiol. 2002; 89:12-17.

[22]. Li C, Hsieh MC, Chang SJ. Metabolic syndrome, diabetes, and hyperuricemia. Current opinion in rheumatology. 2013; 25:210-216. [PubMed: 23370374]

[23]. Osgood K, Krakoff J, Thearle M. Serum Uric Acid Predicts Both Current and Future Components of the Metabolic Syndrome. Metabolic syndrome and related disorders. 2013

[24]. Brady, T. Adenosine Deaminase. Biochem. J.,(1942). 36:478-484.

[25]. Green, A. Adenosine Receptor down-regulation and insulin resistance following prolonged incubation of adipocytes with an A1 adenosine receptor agonist. J. Biol. Chem. (1987). 262, 1502-1507.

[26]. Folli, F.M., Sad, J.M., Backer, J.M. and Hahn, C.R. Insulin Stimulation of phosphatylinositol 3-kinase activity and associated with insulin receptor substrate1 in liver and muscles of the intact rats. J. Bio. Chem, (1992). 267:22171-22177 